\title{
Иноземцев В.И.
}

\section{ПРОБЛЕМЫ ПОВЫШЕНИЯ КАЧЕСТВА СТРОИТЕЛЬСТВА ЖЕЛЕЗНОДОРОЖНЫХ ПУТЕЙ, МОСТОВ И ТРАНСПОРТНЫХ ТОННЕЛЕЙ}

\section{Inozemzev V.I.}

\section{PROBLEMS OF RAILWAYS, BRIDGES AND TRANSPORT TUNNELS CONSTRUCTION QUALITY IMPROVEMENT}

В статье рассматриваются новые материаль и технологии, которые применяются при строительстве железных дорог, в том числе и при их сооружении в особых климатических условиях, в условиях вечной мерзлоты, низких температур и высокогорья.

Рассматривается российский и международный опыт железнодорожного строительства, в частности, в высокогорной части Китая - Тибете.

Ключевые слова: железнодорожный путь, пеноплэкс, строительство, мерзлота, грунт, термосифон.

The article deals with new materials and technologies that are used in the construction of railways, including their construction in special climatic conditions in the permafrost, low temperatures and highland. Russian and international experience in railroad construction, in particular, in the mountainous part of the China-Tibet is taken into consideration

Key words: railway, penoplex, construction, permafrost, soil, thermosyphon .

В современных условиях строительство и ремонт железнодорожных путей требуют значительных капиталовложений. Помимо этого необходимо выяснить геологию на протяжении всего предполагаемого маршрута, так как специфика железнодорожного строительства предъявляет свои требования к геологическому строению участка, по которому будет проходить путь. Правильный выбор маршрута может быть сделан только при условии, что будут выявлены все заводненные территории, болота, водяные линзы, карстровые пустоты и другие особенности геологии. Такие препятствия необходимо миновать, или, если это невозможно, грамотно укрепить несущие конструкции, усилить насыпи и гарантировать высокую безопасность и качество железнодорожного полотна.

Таким образом, строительство нового железнодорожного полотна включает в себя такие этапы как: инженерные изыскания (геологические и топографические работы), предпроектные работы (составление планов и проектов с обоснованием), проектные работы (составление смет), строительно-монтажные работы (подготовка площадки, земляного полотна), строительство железнодорожного полотна и оформление всей необходимой при сдаче в эксплуатацию документации, такой, каким, например, является технический паспорт железнодорожного пути.

Необходимо добавить, что каждый этап строительства должен подвергаться контролю высококвалифицированными специалистами, как и проверка качества выполняемых работ и сроков их проведения.

Транспортные возможности сети железных дорог определяются их несущими способностями, которые зависят не только от прочностных свойств системы, но и ее геометрических параметров, их стабильности, разрушающее влияние которых возрастает с увеличением скоростей движения и осевых нагрузок.

В России и за рубежом стабильность нормативной геометрии железнодорожного пути обеспечивается тремя основными технологиями обработки балластной призмы: подбивкой 
балласта под шпалой, поверхностным уплотнением и динамической стабилизацией пути. Эти технологии характеризуются недостаточной эффективностью: низким качеством уплотнения балласта, интенсивным разрушающим воздействием на путь, недостаточной выработкой в «окно» и т. д.

Какие же существующие и предлагаемые путейской наукой возможности в изыскании, проектировании и строительстве железных дорог должны знать и освоить будущие инженеры - путейцы?

Обобщая лучший зарубежный и отечественный опыт, используя наработки НТЦ НИИОГР и НПП «Инжиниринг-Сервис», входящего в группу компаний «Оптимум», за тридцатилетний период, в начале МПС, а затем ОАО «РЖД» была предложена качественно новая продукция - инструмент, рабочие органы, машины для обработки балласта ж.д. путей. Предлагаемые инновационные технологии позволяют решить проблему обеспечения наилучшей устойчивости и несущей способности железнодорожных путей. Результат достигается через высокопроизводительное предельное уплотнение балласта балластной призмы. Традиционная техника для выправочно - подбивочно-рихтовочных работ (ВПРработ) предлагает горизонтальное виброобжатие и виброуплотнение балласта в слое, который в три раза меньше толщины балластной призмы. Основным средством стабилизации (уплотнения балласта) железнодорожного пути служит сама поездная нагрузка. Она, в свою очередь, приводит к расстройству железнодорожного пути по мере его осадки и к необходимости периодического выполнения дополнительных ВПР-работ. Разработанная в России технология интегральной стабилизации железнодорожного пути (ИСП) при первой же выправке пути обеспечивает наилучшее объемное уплотнение балласта до степени 20\% по всей его толщине, а при повторных работах в процессе обслуживания железнодорожного пути не приводит к разупрочнению балластной призмы. Все это многократно сокращает объем ВПР-работ, «окон», материальных затрат, в первую очередь по скоростным и грузонапряженным маршрутам.

Высокое качество уплотнения ИСП достигается за счет синхронного воздействия активатора, совершающего горизонтальные и вертикальные вибровоздействия на балласт, поверхностного уплотнителя и вертикальных вибраций рельсошпальной решетки, вызванных ИСП. Все это позволяет уплотнять только тот балласт, который уплотняется, и не разуплотнять балласт, который уплотнен, а также максимально исключить разрушающее воздействие на элементы верхнего строения пути в целом.

За последние 20 лет техника и технология ИСП прошли промышленную апробацию в типичных условиях магистральных железных дорог, подтвердив их максимальную эффективность в уплотнении балласта. Ресурсные испытания ИСП указывают на высокие возможности в обеспечении надежности, долговечности и малообслуживаемости данного оборудования (в силу его простоты). Конструкция последних рабочих органов ИСП пятого поколения позволяет их использовать не только при создании новых машин, но и при модернизации существующих ВПР-машин с многократным повышением их техникоэкономической эффективности.

Среди новых материалов, нашедших признание при строительстве и ремонте железнодорожных путей, плиты "Пеноплэкс" марки 45.На протяжении последних лет они широко используются в качестве морозозащитного слоя при реконструкции балластной призмы железнодорожных линий.

Материал был доработан в соответствии с техническими требованиями МПС РФ, принятыми, затем ОАО «РЖД» и в настоящее время плиты поставляются с обработкой кромок специальной формы. Применение плит "Пеноплэкс" разрешено на основании цикла испытаний лаборатории пути МГУПС и регламентировано нормативными документами Департамента пути и сооружений ОАО «РЖД»:

- Технические указания на применение пенополистирола и геотекстиля при усилении основной площадки земляного полотна без снятия рельсошпальной решетки; 
- Стандартные проектные решения и технологии усиления земляного полотна при подготовке полигонов сети для введения скоростного движения пассажирских поездов.

Плиты “Пеноплэкс" доказали свою эффективность и применяются на десяти железных дорогах России: Восточно-Сибирской, Свердловской, Горьковской, Западно-Сибирской, Северной, Октябрьской, Дальневосточной, Куйбышевской, Красноярской, Московской. Кроме того, при устройстве железнодорожного полотна на пролетные строения лоткового типа с целью защиты гидро- и шумоизоляции от механических повреждений в процессе эксплуатации разработана и успешно применяется конструкция с использованием плит пеноплэкса, примененная в 2002 году при строительстве Ладожского вокзала в СанктПетербурге и мостового перехода около поселка Веребье (Октябрьская железная дорога).

Основная эксплуатационная проблема железных дорог, проложенных в районах с суровыми зимами, - это деформация земляного полотна от сил морозного пучения. В холодное время года в теле насыпи насыщенном водой при промерзании образуются ледяные линзы, которые неравномерно приподнимают балластную призму и путевую решетку, вызывая первые деформации железнодорожного полотна.

$\mathrm{C}$ наступлением теплого времени года ледяные линзы внутри грунта оттаивают, превращаясь вновь в воду, и эта влага сильно влияет на прочностные характеристики грунтов. Происходит разжижение и осадка несущих слоев насыпи. На протяжении нескольких сезонов холодного и теплого периодов на структуру железнодорожного полотна оказывается многократное воздействие неравномерного подъема-опускания и вырабатывается так называемый "ходячий зазор", что влечет за собой частичную деформацию рельсошпальной решетки и, как следствие, ухудшается характеристика надежности безопасности движения.

Для наибольшей эффективности эксплуатации дорог в нашей стране оптимальная скорость движения составов может достигать 120-140 км/час, требования к обеспечению устойчивой и безопасной работы полотна существенно возрастают. В условиях же промерзающих грунтов безопасность движения без постоянной планово-предупредительной выправки и ремонта пути может достигаться только значительным снижением скорости прохождения подвижного состава.

Учитывая данные обстоятельства, ОАО «РЖД» активно разрабатывало различные методы борьбы с этой проблемой и в последние годы активно исследовало наиболее эффективные современные способы предохранения железнодорожного полотна от морозного пучения. Были изучены результаты технологических решений, применявшиеся ранее в Российской Федерации, а так же современный опыт наших соседей - Норвегия, Швеции, Австрии, Германии. В технологии поддержания постоянного безопасного качества железнодорожного полотна существуют различные способы.

- Это может быть полная замена грунта на проблемных участках пучинистых грунтов. Для этого требуется его разработка, вывозка и замена на качественные крупно и среднезернистые пески. При производстве работ необходимо дополнительное укрепление откосов щитами для ликвидации осыпей. Кроме этого, необходимо вводить во временную эксплуатацию второй путь на период реконструкции или использовать большое количество транспортных средств для вывоза старого грунта, что уже само по себе значительно увеличивает затраты на реконструкцию земляного полотна.

- Это может быть создание морозозащитного слоя из теплоизоляционных материалов. В качестве теплозащитного слоя ранее использовался пенополистирол и асбестовый щебень, но опыт показал недостаточную прочность и долговечность этих материалов.

В настоящее время одним из вариантов усиления основной площадки земляного полотна (по схеме: эффективность равна: затраты плюс технологичность плюс долговечность) был выбран метод устройства защитного слоя из экструзионного(синтетический теплоизоляционный материал) пенополистирола (рис. 1).

Этот метод реконструкции железнодорожных путей в испытаниях занял особое место по основным показателям и был признан как наиболее эффективный в неблагоприятных 
условиях: при затрудненном поверхностном водоотводе и в зонах повышенных силовых воздействий.

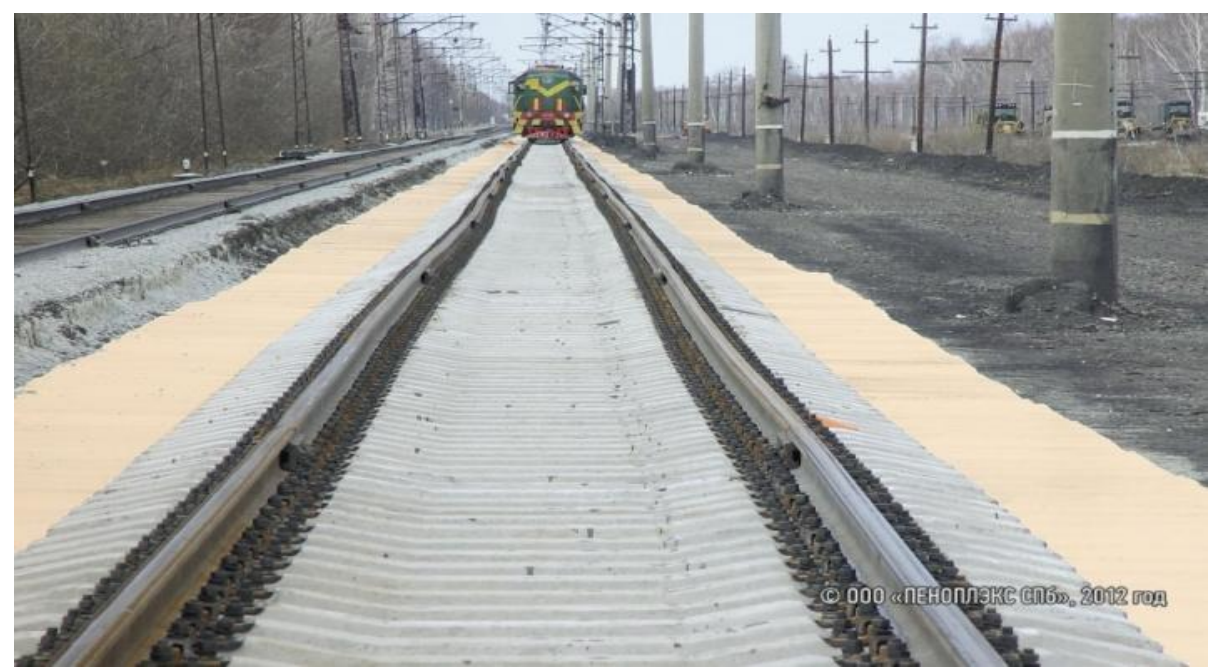

Рисунок 1- Укладка плит марки «Пеноплекс - 45»

При производстве работ применяются специальные путевые ремонтные машины типа РМ-80 или "Самсон", которые позволяют:

- работать на путях с использованием 6-8 часовых «окон» в движении поездов;

- выемку, очистку и укладку гравия производить практически одновременно и без остановок;

• укладку изолирующих плит производить параллельно с заменой щебеночного балласта.

Таким образом, применение специализированной техники при реконструкции полотна позволяет максимально использовать рабочий график движения поездов, работая в окнах движения. На основании вышеизложенного можно сделать вывод: высокоэффективный изолирующий материал - экструзионный пенополистирол марки «Пеноплэкс-45» позволяет добиться хороших показателей защиты земляного полотна от климатологических воздействий, тем самым увеличивая эксплуатационную безопасность и долговечность железных дорог страны.

На сегодняшний день основу большегрузных перевозок составляют железные дороги. Сегодня темпы строительства железных дорог уже значительно меньше, но и сегодня новые железные дороги строятся в разных частях России.

Большая часть железных дорог строится на Дальнем Востоке и Сибири. Развитие дорожной системы этих регионов позволит доставлять полезные ископаемые в центральную часть России и перерабатывать их на предприятиях. Кроме полезных ископаемых на железнодорожном транспорте возможна перевозка различных товаров.

В настоящее время Арктика рассматривается многими государствами как стратегический регион в связи с колоссальными запасами углеводородов и усилением роли факторов и условий, лежащих в основе политической и энергетической безопасности ведущих индустриально развитых стран мира. Так, одним из перспективных направлений может стать полномасштабная реализация транспортно-транзитного потенциала за счет становления системы международных транспортных коридоров, проходящих по территории и акватории под юрисдикцией Российской Федерации, а также капиллярной транспортной инфраструктуры, связывающей труднодоступные приарктические населенные пункты.

Россия уже сегодня обладает уникальными транспортно-логистическими возможностями, которые благодаря естественным природным предпосылкам могут в значительной мере содействовать ее превращению в конкурентоспособное транзитное государство с развитой сферой услуг и сервисной экономикой. 
Развитие полноценной транспортной системы и инфраструктуры позволит не только преодолеть барьеры в использовании транзитного потенциала и повысить транспортную доступность населенных пунктов, но и во многом устранить инфраструктурные ограничения на рост добычи полезных ископаемых в арктической зоне России (АЗР).

Очевидно, что без дальних железнодорожных подходов развитие арктических портов имеет низкую перспективность

Именно поэтому проект "Белкомур" является наиболее перспективным и имеет благоприятные условия для реализации. Проект имеет более чем 100-летнюю историю. Первые официальные упоминания о планах строительства железнодорожной магистрали, которая должна соединить промышленные районы Урала с Белым морем относятся к 1912 году. Начало реализации проекта - строительство участков Архангельск-Карпогоры и Вендига-Микунь пришлось на 1947-1954 гг., когда было построено более 400 км железной дороги.

Название "Белкомур" ("БЕлое море-КОМи-УРал") проект получил в 1995 году, когда было начато строительство на участках Карпогоры-Шарда (22 км) и Ертом-Вендига 18 км). Он предусматривает строительство недостающих участков (Карпогоры-Вендинга) железной дороги по трассе Архангельск-Пермь для связи Архангельского морского порта с Сыктывкаром, Кудымкаром и Пермью (Соликамском). Это обеспечит выход продукции этих регионов на внешние рынки. В связи с этим особенно актуализируется реализация таких проектов, как строительство технологических линий Сосногорск-Индига ("Баренцкомур"), Воркута-Усть-Кара, а также коридора "Север-Юг", предназначенного для транспортного сообщения между государствами Персидского залива, Индией, Пакистаном через Каспий со странами Восточной и Центральной Европы и Скандинавии.

Более того, строительство железной дороги Полуночная-Обская, достройка линии Обская-Бованенково с последующим выходом на порт Харасавэй, создание железнодорожного сообщения Надым-Салехард и далее до Лабытнанги, а также линии Коротчаево-Игарка с перспективой выхода на Дудинку и Норильск позволят связать рудные ресурсы полярного Урала, зону нефтегазодобычи Ямала с освоенными районами промышленного Урала.

Новые железные дороги меридионального направления, выходящие к портам Белого, Баренцева, Карского морей и моря Лаптевых, увеличат грузовой потенциал Северного морского пути (СМП) и откроют прямой выход в Западную Европу. Более сложные последствия может иметь строительство железнодорожной линии Салехард-Надым-Новый Уренгой с выходом на Игарку и Норильск, поскольку появляется риск оттока грузов с наиболее развитого на СМП дудинского направления.

Проект "Белкомур" прошел все необходимые согласования в министерствах и ведомствах, был утвержден Министерством транспорта РФ

Учитывая предстоящие перспективы строительства железных дорог на Арктических территориях в условиях сурового климата и вечной мерзлоты, необходимо подробно познакомиться с опытом строительства в подобных условиях железных дорог в Северной Америке и, особенно, в высокогорном районе Китае-Тибете. На строительстве этой, как её часто называют самой «экстремальной дорогой мира» китайскими инженерами путейцами, были предложены, разработаны и внедрены оригинальные решения для устойчивой работы железнодорожного полота, что позволило открыть постоянное движение поездов по Цинхай -Тибетской железнодорожной магистрали, строительство которой длилось почти полвека. Общая длина Цинхай -Тибетской железной дороги от Синина до Лхасы составляет 1956 километров, средняя высота свыше 4000 метров над уровнем моря. Строители ЦинхайТибетской железной дороги работали в суровом климате. Температура иногда подала до минус $45 \mathrm{C}^{\circ}$. Число дней с сильным ветром составляло до 160 дней в год. Кроме того, нехватка кислорода на такой высоте была серьезной проблемой. Железная дорога строилась в необитаемых и безлюдных районах. 550 километров этой дороги строилась в зоне вечной мерзлоты нагорья. В ходе строительства особое внимание уделялось сохранению природы. 
Строительство подобной железной дороги еще не знала ни китайская, ни мировая история строительства железных дорог. Однако миллионная армия строителей, проявляя новаторский дух и придерживаясь научного подхода, смогла преодолеть трудности строительства и успешно разрешить сложнейшие технические проблемы строительства в условиях мерзлоты, имеющие глобальный характер. Переменное состояние такой почвы приводит к разрушению железнодорожного полотна, появлению трещин на нем или зданий. Как свидетельствуют данные России от 1994 года, в 70-годах 20 века во время строительства второго транссиба 27,5 \% железнодорожного полотна пострадали от различных отрицательных воздействий почвы. Согласно данным Китая от 1990 года, такой показатель на Цинхай-Тибетском шоссе составляет $31,7 \%$. В силу отрицательных воздействий мерзлой почвы в мире поезда на таких железных дорогах могут ехать только со скоростью не больше 50 километров. Максимальная скорость движения поездов на Цинхай -Тибетской железной дороге в зоне высокогорной тундры составит 100 км/ч, в других районах до 120 км/ч. Каждый вагон обеспечивается дополнительным кислородом для предотвращения кислородного голодания. Предусмотрена также защита от солнечной радиации.

Цинхай-Тибетская железная дорога проходит через горы Куньлунь, Тангла. Самая высокая точка дороги находится на высоте 5072 метров над уровнем моря. Условия строительства были очень сложными - наличие заболоченной местности, мерзлой почвы, высокая температура поверхности земли летом. Все это были сложнейшие технологические трудности. Хотя в Канаде, России и других странах также существует мерзлая почва, но в силу того, что они расположены в высоких широтах, такая почва более прочная и стабильная. А на участках Цинхай-Тибетской железной дороги от Гээрму до Лхасы в силу низкой широты и высоты местности, большого солнечного излучения, мерзлая почва имеет свои сложнейшие свойства. Тем не менее, для решения проблем, возникавших при строительстве, были приглашены российские инженеры, имеющие немалый опыт по сооружению железных дорог в схожих геологических условиях, прежде всего, во время строительства Байкало-Амурской магистрали. Огромная роль в проектировании магистрали, разработке технических рекомендаций по укладке пути в условиях вечной мерзлоты и высокой сейсмичности принадлежит профессору МИИТа Г. М. Шахунянцу.

Китайские специалисты при сооружении полотна Цихай-Тибетской железной дороги использовали метод укладки особого слоя из щебня между полотном и пластом вечной мерзлоты, чтобы предотвратить ее таяние. Оригинальные решения были предложены профессором Ню Фуджином. Были установлены так называемые "тепловые трубы" остроумное приспособление для борьбы с разморозкой грунта. Труба наполнена жидким аммиаком. Когда аммиак нагревается, он в газообразном состоянии поднимается по трубе, через ребра отводится тепло, газ конденсируется и стекает по трубе вниз (рис.2).
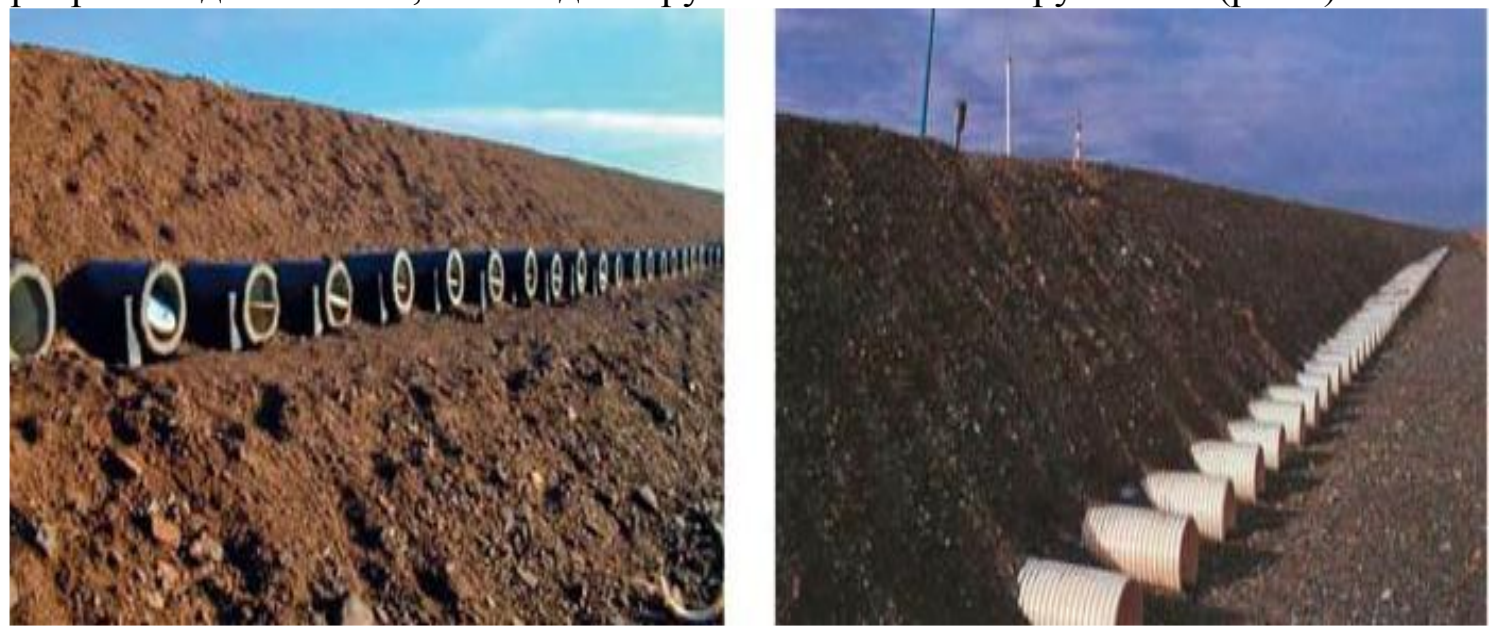

Рисунок 2- Поперечные вентилируемые трубы в основании земляного полотна 
По предложению российских специалистов на Цинхай -Тибетской железной дороге успешно реализовано и другое техническое решение - насыпь с поперечными охлаждающими трубами. При этом были применены, как железобетонные, так и пластмассовые трубы, варьировались высота над подошвой насыпи и шаг укладки труб. Для эффективной работы поперечных охлаждающих труб необходимо закрывать их отверстия на теплый период года и открывать с наступлением зимы. Для этого были применены автоматические заслонки.

На строительстве китайскими инженерами был применен и ряд собственных, смелых технических решений. Во многих местах использован так называемый «сухой мост»эстакадный переход участков льдистых вечномерзлых грунтов. Самый длинный «сухой мост» имеет длину 11,7 км и опирается на 2878 опор (рис.3).

Пригодился опыт российских инженеров и во время прокладки тоннелей. Ведь самый высокогорный в мире туннель строился в местах вечной мерзлоты. Протяженность туннеля-1338 метров, железнодорожное полотно находилось на высоте 4905 метров над уровнем моря (рис.4). Отсюда можно судить, сколько сложнейших технических проблем было разрешено и в каких трудных условиях проходило строительство этой железной дороги.

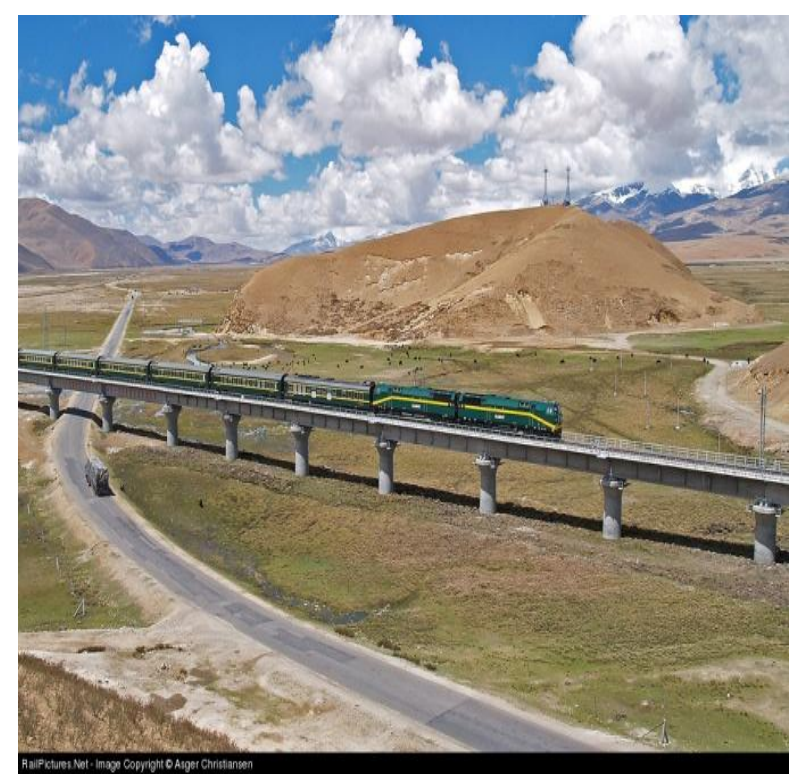

Рисунок - 3 Сухой мост»

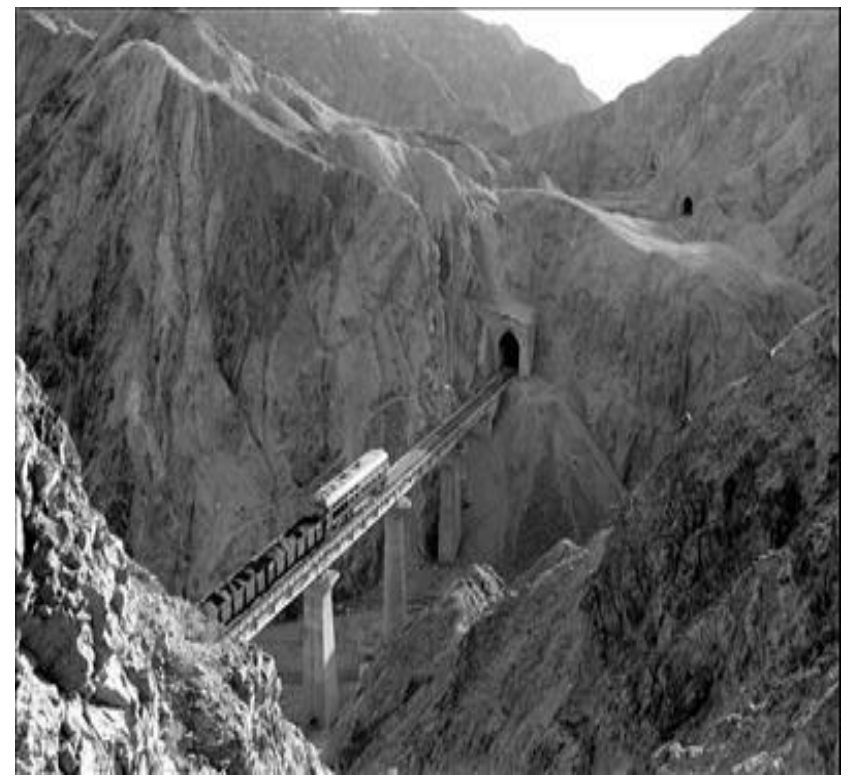

Рисунок 4 - Самый высокогорный в тоннель

Этот опыт, несомненно, должен быть учтен в России, где возобновляется строительство новых железных дорог в районах с вечной мерзлотой и глубоким сезонным промерзанием грунтов, в частности, при проектировании и строительстве новой железнодорожной линии Нарын - Лугокан для освоения полезных ископаемых на юго - востоке Забайкальского края, а также при завершении строительства Амуро - Якутской железнодорожной магистрали и в особенности при стабилизации земляного полотна на участках льдистых грунтов Забайкальской, Дальневосточной и Восточно - Сибирской железных дорог в составе обновления инфраструктуры по Инвестиционной программе ОАО «РЖД».

Поэтому развитие и строительство железных дорог в этих регионах в ближайшем будущем должно стать реальностью.

Строительство, реконструкция, усиление и ремонт железнодорожных путей для скоростного движения в России, в том числе в Дагестане, в настоящем и ближайшем будущем потребует высококвалифицированных специалистов - путейцев и эксплуатационников, которых подготавливают в ДГТУ. 


\section{Библиографический список:}

1. . Железные дороги мира. 2011-2012 C-84

2. Коновалов А.М. Транспортная инфраструктура российской Арктики: проблемы и пути их решения // Арктика: зона мира и сотрудничества / Отв. ред. А.В. Загорский.М. ИМЭМО PAH, 2011.C -195

3. Кондратьев.В.Г. Опыт строительства и проблемы стабильности земляного полотна Цинхай - Тибетской железной дороги на участках вечной мерзлоты. Ж. Транспорт Российской Федерации.№ 6(25).2009.С-61.

4. Проектирование железнодорожного пути. Под ред. Г.М.Шахунянца. - М.: "Транспорт", 1972 г.- 320 c

5. Сооружение земляного полотна в сложных условиях: Учеб. пособие / Г.Л. Шалягин, Э.С. Спиридонов, М.С. Клыков и др.; Под ред. М.С. Клыкова. - Хабаровск: Изд-во ДВГУПС, 2005. - C -131.

6. Шахунянц Г.М. Железнодорожный путь. Учебник для. М. Транспорт. 1981г. С -536 .

7. Яковлева Г.Т. «Железнодорожный путь». М.Транспорт.1999.С - 406.

УДК 624.131.3.

Аллаев М. О.

\section{МЕТОДЫ ПРОГНОЗА БЕЗОПАСНОЙ РАБОТЫ ЗЕМЛЯНОГО ПОЛОТНА АВТОМОБИЛЬНОЙ ДОРОГИ}

Allaev M.O.

\section{METHODS OF THE FORECAST OF SAFE WORK OF A ROAD BED OF THE HIGHWAY}

В статье приведень методы прогноза параметра безопасной работы земляного полотна, в качестве которого принята надежность работы за период между капитальными ремонтами при нормальных условиях эксплуатащии. Рассматривается надежность как оценка вероятности невыхода процесса за допустимые интервальи и время, в течение которого не осуществляется такой выход. Геотехнические процессы, имеющие место во время эксплуатации земляного полотна, представлены как квазистационарные и стационарные случайные прочессы. Получены выражения по прогнозированию времени достижения заданной вероятности отсутствия выброса, и, наоборот, по нахождению вероятности отсутствия (времени) выброса за фиксированный период времени.

Ключевые слова: основание, вероятность, изменчивость, прочесс, время, прогноз, дисперсия, надежность, выброс.

Methods of the forecast of the parameter of the safe work earth are brought In article onpallet, as which is accepted reliability of the work for period between heavy repairs at reasonable conditions of the usages. Reliability is Considered as estimation to probability of the failure to appear of the process for possible intervals and time, during which is not realized such output. Geotehnicheskie processes, having place during usage of the earth linen, are presented as quasistationary and stationary casual processes. Expressions are Received on forecasting of time of the achievement given probability of the absence of the surge, and, on the contrary, on finding of probability of the absence (time) of the surge for fixed length of time.

Key words: base, probability, variability, process, time, forecast, dispersion, reliability, surge 